\title{
Non-Uniform Occurrence of Short-Term Polarity Fluctuations in the Geomagnetic Field? New Results From Middle to Late Miocene Sediments of the North Atlantic (DSDP Site 608)
}

\author{
Wout Krijgsman \\ Paleomagnetic laboratory "Fort Hoofddijk", Utrecht University, The Netherlands \\ Dennis V. Kent \\ Department of Geological Sciences, Rutgers University, Piscataway, New Jersey, and \\ Lamont-Doherty Earth Observatory, Palisades, NewYork
}

New magnetostratigraphic results from DSDP Site 608 in the North Atlantic reveal the presence of nine short-term polarity fluctuations that do not correspond to subchrons in the most recent GPTS. Comparison with published results from ODP Sites 845 and 1092, and from the continental Orera Composite Section, shows that all these polarity fluctuations are observed in more than one record. At DSDP Site 608 , five of the intervals are ascertained by more than two samples and have an estimated duration that is larger than $10 \mathrm{kyr}$. We regard these as polarity subchrons, which define five new short polarity intervals in the Miocene: C4r.2r-1n, C4Ar.1r1n, C5r.2r-1n, C5r.2r-2n, and C5r.3r-1n. Three polarity fluctuations within C5n and one in C5An.2n are each only determined by one sample and are hence not unambiguous. They have an estimated duration $<10 \mathrm{kyr}$ and an inconsistent expression. Consequently, we believe they qualify better as directional excursions and that they are most likely associated with decreases in paleointensity (DIPs) of the geomagnetic field. The identification of these nine new magnetic events suggests that the occurrence of short-term polarity fluctuations in the geomagnetic field is indeed non-uniformly distributed through time. For example, they are relatively more common in the early Late Miocene and the Pleistocene but virtually absent in the latest Miocene and Pliocene. It remains uncertain, however, if this is related to real behavior of the geodynamo. The detection of several new short polarity subchrons in the Middle to Late Miocene time interval may be explained by earlier registration problems in the magnetic anomaly patterns, while the absence of such features in the latest Miocene-early Pliocene could be related to paleomagnetic records of inferior data quality.

Timescales of the Paleomagnetic Field

Geophysical Monograph Series 145

Copyright 2004 by the American Geophysical Union

$10.1029 / 145 \mathrm{GM} 12$

\section{INTRODUCTION}

One of the most fascinating characteristics of the Earth's magnetic field is that the dipole undergoes complete polarity 
reversals a few times every million years on average. The intervals between reversals have a stable normal or reversed polarity and are called subchrons, chrons, and superchrons, depending on their duration. They define a characteristic pattern of polarity zones through time and, as such, form a fundamental tool for dating of the geological record: the geomagnetic polarity time scale (GPTS). The reliability and completeness of this GPTS is crucial for geochronology but also for understanding the long-term statistical properties of the geomagnetic field. The shortest polarity intervals in the most recent GPTS (CK95 of Cande and Kent [1995]) are typically on the order of $30 \mathrm{kyr}$ in duration, but the magnetic anomaly patterns of fast spreading oceanic plates indicate that smaller-scale variations, so-called 'tiny wiggles', exist as well [Cande and Kent, 1992a, 1992b; Bowers et al., 2001]. The origin of 'tiny wiggles', whether they represent short polarity subchrons or mainly decreases in paleointensity is unclear, and consequently they have been referred to as cryptochrons [Cande and Kent, 1992a, 1992b]. Detailed and numerous paleomagnetic investigations of the youngest period of the geological record also revealed the presence of many shorter periods of anomalous field behavior referred to as excursions, relatively brief deviations in directions that are larger than what might be expected from normal secular variation and that are usually accompanied by substantial decreases in paleointensity [for a review see Langereis et al., 1997; Lund et al., 1998]. An ongoing debate, parallel to that for cryptochrons, is which excursions qualify as records of short polarity subchrons.

Numerous short-term polarity fluctuations are considered to be an intrinsic part of Earth's magnetic field behavior according to the most recent studies on the geodynamo [Gubbins, 1999]. In contrast to this, the occurrence of cryptochrons or excursions in the geological record seems rather non-uniformly distributed through time. They are common in latest Pliocene to Pleistocene (2-0 Ma), middle to early Late Miocene (11-8 Ma), Oligocene (30-24 Ma), and Paleocene (61-53 Ma) records, but seem to be largely absent in records of the latest Miocene and most of the Pliocene, Early Miocene, and Eocene [Cande and Kent, 1992a]. The main question associated with these intervals when cryptochrons or excursions are apparently absent is whether they are related to different behavior of the geodynamo or to registration problems of the paleomagnetic signal. Variation in data quality may thus contribute to the apparent irregularity in the temporal distribution of cryptochrons and excursions.

The registration and characterization of short polarity subchrons and excursions in the geological record obviously require a high-resolution sampling and an accurate determination of the paleomagnetic signal, which are not always available. Especially in the Brunhes $(\mathrm{C} 1 \mathrm{n})$ and Matuyama $(\mathrm{C} 1 \mathrm{r})$ chrons, numerous high-resolution and high-quality paleomagnetic records from complete stratigraphic sequences and detailed volcanic successions are available and many of them reveal the existence of excursions [Langereis et al., 1997; Lund et al., 1998; Singer et al., 1999; Channell et al., 2002]. Detailed comparison of these records, however, commonly reveals significant inconsistencies in the age, duration and the number of registered events. In addition, numerous MioPliocene sections-both in continental and marine environments-have been sampled for the construction of the Mediterranean-based astronomical polarity time scale (APTS) with a sufficiently high resolution to detect cryptochrons [Langereis and Hilgen, 1991; Krijgsman et al., 1995; Van Vugt et al., 1998; Garcés et al., 2001]. So far, no solid evidence has been provided for the existence of excursions in records for this time span. This seems to be in agreement with the apparent lack of cryptochrons in the Late Miocene to Early Pliocene ocean floor anomaly patterns [Cande and Kent, 1992a]. Recent attempts to extend the Mediterranean APTS downward in time revealed again the presence of several excursions in the Middle to Late Miocene interval [ $\mathrm{Abdul}$ Aziz et al., 2000,2003]. This suggests that the occurrence of short-term polarity fluctuations of the geomagnetic field might indeed be restricted to specific intervals in geological history.

The validity of a new subchron at a certain age and location obviously requires confirmation by other records from different parts of the world. For the Middle to Late Miocene interval, the existence of features that may correlate with magnetic anomaly cryptochrons has been reported from continental records [Tauxe and Opdyke, 1982; Garcés et al., 1996; Li et al., 1997a, 1997b; Rösler and Appel, 1998; Roperch et al., 1999], and also from detailed magnetostratigraphic studies on cores of the Deep Sea Drilling Project (DSDP) or its successor, the Ocean Drilling Program (ODP) [Schneider et al., 1997; Roberts and Lewin-Harris, 2000; Bowles et al., 2003; Evans and Channell, 2003]. In this study, we present new paleomagnetic results from a detailed re-sampling of the middle to early Late Miocene interval of DSDP Site 608, which contains one of the best and most complete magnetostratigraphic records of this interval in the world [Clement and Robinson, 1986].

\section{DSDP LEG 94; SITE 608}

During DSDP Leg 94, sediment was recovered from 22 holes at six sites in the North Atlantic. The primary objective of this leg was to obtain a continuous high-resolution paleoclimatic record along a transect from $35^{\circ} \mathrm{N}$ to $55^{\circ} \mathrm{N}$ in the North Atlantic [Ruddiman et al., 1987]. Paleomagnetic, stable isotope, calcareous nannofossil, foraminiferal, diatom, radiolarian, and dinocyst stratigraphic studies have been per- 
formed and made these records a reference section for Miocene isotope studies [Clement and Robinson, 1986; Miller et al., 1991; Gartner, 1992]. The reliable magnetostratigraphic results, the near-complete recovery, and the abundant fossil content of the sediment provided a time framework in which the paleoclimatic, paleoceanographic, tectonic, and other studies of these sediments could be integrated and together correlated with the GPTS. Site 608 was drilled on the southern flank of the King's Trough tectonic complex, a series of roughly parallel basins and ridges situated $700 \mathrm{~km}$ northeast of the Azores (Figure 1). Hole 608 was continuously cored with the variable-length hydraulic piston corer and extended core barrel to basement at 530.9 meters below sea-floor (mbsf) [Ruddiman et al., 1987]. Core recovery was generally over $90 \%$, and an almost continuous stratigraphic sequence was recovered from the mid-upper Oligocene to the Pleistocene. Sediment accumulation rates averaged between 3 and $5 \mathrm{~cm} / \mathrm{kyr}$, which allowed the delineation of a detailed magnetic polarity stratigraphy [Clement and Robinson, 1986]. Subsequent shore-based additional sampling and laboratory work were done to refine the polarity records [Miller et al., 1991].

The magnetostratigraphic records of the Plio-Pleistocene interval of the Leg 94 sites could be correlated straightforwardly to the GPTS. Moreover, several excursions were observed in the high-resolution records of several holes, which correlated to the Cobb Mountain (1.20-1.21 Ma), 'Gilsa' ( $1.58 \mathrm{Ma})$, and Réunion (2.14-2.15 Ma) events [Clement and Robinson, 1986; Clement and Kent, 1987]. Correlation of the Miocene polarity $\log$ of Site 608 with the GPTS also seems unambiguous, especially with the presence of a 40 meterthick normal polarity interval in cores 23 through 27 that represents chron C $5 \mathrm{n} .2 \mathrm{n}$, and is furthermore supported by biostratigraphic data. In several intervals, the Miocene polarity pattern of Site 608 shows even more detail than the standard GPTS. This could indicate additional polarity subchrons that were previously not registered in the polarity time scale.

\section{NEW MAGNETOSTRATIGRAPHIC RESULTS FROM DSDP SITE 608}

\subsection{Methods}

The original magnetostratigraphy of Site 608 was measured with a fluxgate spinner magnetometer with shorebased work on a cryogenic [Clement and Robinson, 1986]. Several pilot samples were subjected to progressive partial alternatingfield (AF) demagnetization, which showed that unstable or secondary components were readily removed by $10 \mathrm{mT}$ [Clement and Robinson, 1986]. In addition, a stable component was identified by a linear trajectory that decayed toward the origin at higher fields. On the basis of these results, most samples were demagnetized in only one step of $10 \mathrm{mT}$ [Clement and Robinson, 1986].

For our study, the working halves of cores 19 to 34 stored in the ODP East Coast Repository at Lamont-Doherty Earth Observatory (LDEO) - were initially sampled with a resolution of $25 \mathrm{~cm}$, which should correspond to a temporal resolution of approximately $5-10 \mathrm{kyr}$. All intervals containing polarity reversals and potential subchrons were then re-sampled in higher detail to pinpoint the directional changes as exactly as possible. The resulting 585 samples were stepwise AF-demagnetized with standard fields of 5, 10, 15, 20, 30, 40 $\mathrm{mT}$, and measured on a $2 \mathrm{G}$ Model $760 \mathrm{DC}$-Squid 3-axis cryogenic magnetometer housed in a shielded room at the pale-
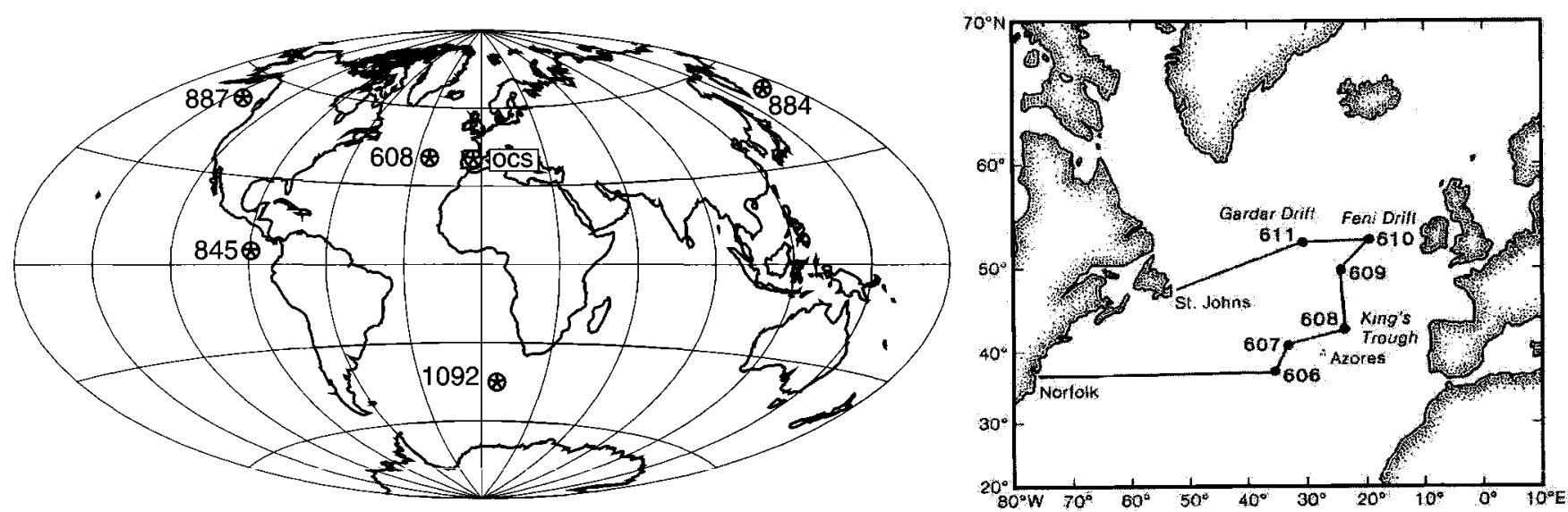

Figure 1. Location map of DSDP Leg 94, with Site 608 located at the southern flank of the King's Trough tectonic complex [after Ruddiman et al., 1987]. On world map are also the locations of the other sites and sections that are discussed in this paper. 


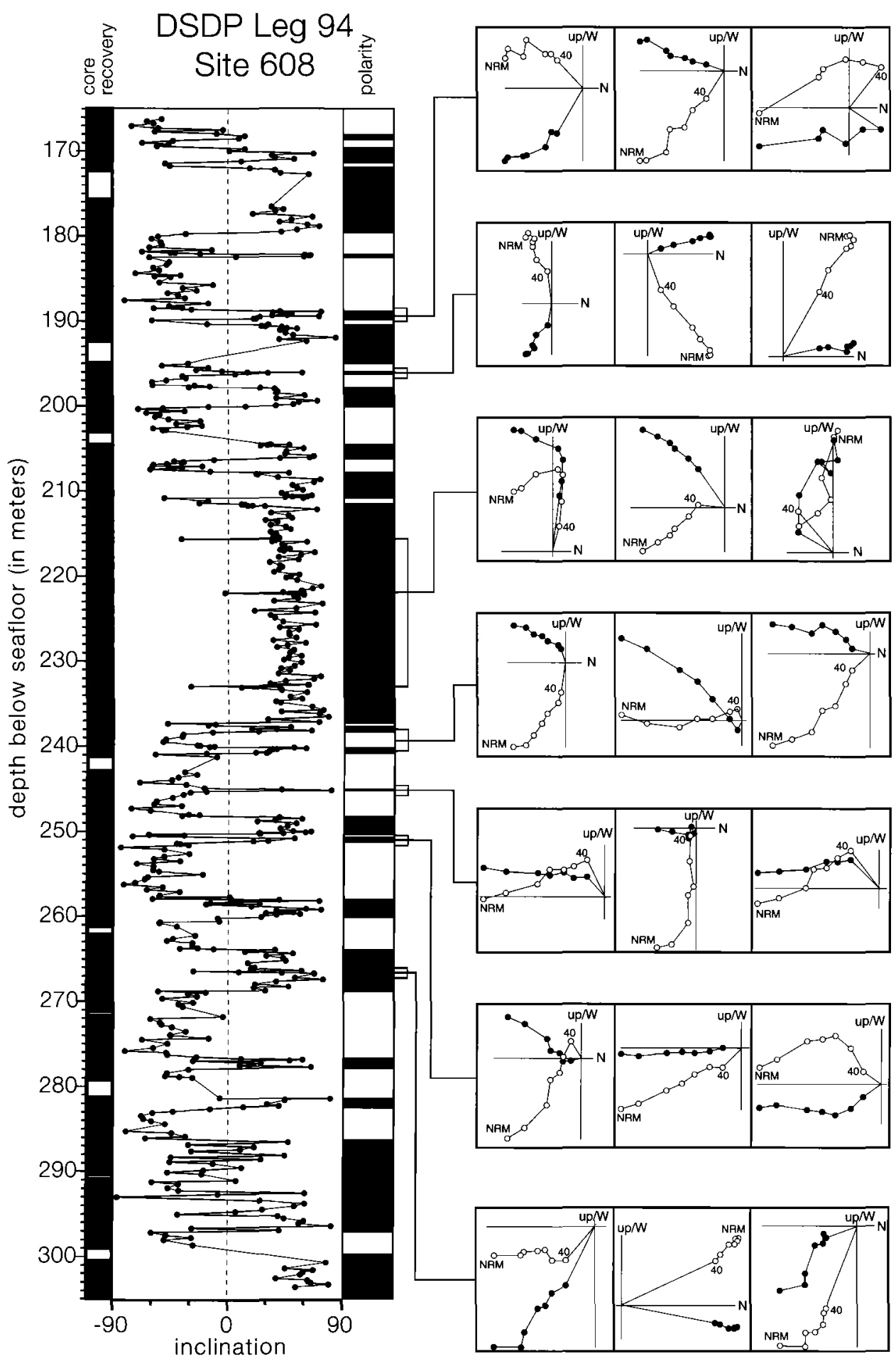

Figure 2. Paleomagnetic results from DSDP Site 608. On the left is the stratigraphic record of the vector end-point component of the inclination record after stepwise AF-demagnetization. In the polarity column black (white) denotes normal (reverse) polarity; gray shading indicates an interval of uncertain polarity. Core recovery is indicated by black colors. On the right are Zijderveld diagrams of all the intervals that contain evidence for short-term polarity excursions. Closed (open) symbols represent projections of vector end-points on the horizontal (vertical) plane after AF-demagnetization with steps of $5,10,15,20,30$, and $40 \mathrm{mT}$ 
omagnetic laboratory of LDEO (Figure 2). Principal component analysis was applied to determine the component directions of the NRM, chosen by inspection of vector endpoint demagnetization diagrams. Especially the lower part of the sequence revealed demagnetization diagrams where the secondary component was only removed at fields significantly higher than $10 \mathrm{mT}$, which showed that the extra effort of stepwise demagnetization was crucial to obtain reliable data (Figure 2). The sediments of cores 29 through 34 were frequently brecciated and intervals suitable for sampling were often difficult to find [Clement and Robinson, 1986]. Consequently, the data from this part of the section were generally of poorer quality.

Table 1. Position in meters below seafloor (mbsf) of the magnetic reversals in DSDP Site 608

\begin{tabular}{|c|c|c|c|}
\hline $\begin{array}{l}\text { Magnetic } \\
\text { reversal }\end{array}$ & $\begin{array}{l}\text { Site } 608 \\
\text { depth (mbsf) }\end{array}$ & $\begin{array}{l}\text { GPTS } \\
\text { age }\end{array}$ & $\begin{array}{c}\text { APTS } \\
\text { age }\end{array}$ \\
\hline C3Br.2n (y) & $168.19-167.96$ & 7.341 & 7.455 \\
\hline C3Br.2n (o) & $168.74-168.51$ & 7.375 & 7.492 \\
\hline $\mathrm{C} 4 \mathrm{n} \cdot \ln (\mathrm{y})$ & $169.72-169.45$ & 7.432 & 7.532 \\
\hline$C 4 n \cdot \ln (0)$ & $171.48-171.24$ & 7.562 & 7.644 \\
\hline $\mathrm{C} 4 \mathrm{n} \cdot 2 \mathrm{n}(\mathrm{y})$ & $172.01-171.80$ & 7.650 & 7.697 \\
\hline $\mathrm{C} 4 \mathrm{n} .2 \mathrm{n}(\mathrm{o})$ & $179.64-179.61$ & 8.072 & 8.109 \\
\hline$C 4 r \cdot \ln (y)$ & $182.18-182.09$ & 8.225 & 8.257 \\
\hline$C 4 r \cdot \ln (0)$ & $182.49-182.48$ & 8.257 & 8.303 \\
\hline C4An $(y)$ & $190.44-190.38$ & 8.699 & 8.750 \\
\hline C4An (o) & $195.02-192.42^{*}$ & 9.025 & 9.075 \\
\hline C4Ar.ln (y) & $197.83-197.80$ & 9.230 & 9.280 \\
\hline C4Ar.1n (o) & $200.07-200.05$ & 9.308 & 9.377 \\
\hline C4Ar.2n (y) & $204.53-202.89^{*}$ & 9.580 & 9.629 \\
\hline C4Ar.2n (o) & $206.34-206.32$ & 9.642 & 9.679 \\
\hline $\mathrm{C} 5 \mathrm{n} \cdot \ln (\mathrm{y})$ & $207.85-207.74$ & 9.740 & ------- \\
\hline C5n.1n (o) & $210.81-210.80$ & 9.880 & ------ \\
\hline $\mathrm{C} 5 \mathrm{n} .2 \mathrm{n}(\mathrm{y})$ & $211.55-211.45$ & 9.920 & ------- \\
\hline C5n.2n (o) & $237.38-237.24$ & 10.949 & 11.053 \\
\hline C5r.1n (y) & $237.75-237.60$ & 11.052 & 11.122 \\
\hline C5r.1n (o) & $238.39-238.28$ & 11.099 & 11.158 \\
\hline C5r.2n (y) & $248.32-248.23$ & 11.476 & 11.558 \\
\hline C5r.2n (o) & $250.37-250.31$ & 11.531 & 11.629 \\
\hline C5An. $\ln (\mathrm{y})$ & $258.05-257.95$ & 11.935 & 12.028 \\
\hline C5An. 1 n (o) & $260.25-260.07$ & 12.078 & 12.127 \\
\hline C5An.2n (y) & $263.94-263.89$ & 12.184 & 12.214 \\
\hline C 5 An. $2 n(0)$ & $268.85-268.80$ & 12.401 & 12.447 \\
\hline C5Ar.1n $(y)$ & $276.75-276.59$ & 12.678 & 12.757 \\
\hline C5Ar.1n (o) & $277.82-277.76$ & 12.708 & 12.780 \\
\hline C5Ar.2n (y) & $281.46-281.39^{*}$ & 12.775 & 12.816 \\
\hline C5Ar.2n (o) & $282.66-282.42$ & 12.819 & 12.881 \\
\hline
\end{tabular}

Ages are in Ma according to the GPTS [Cande and Kent, 1995] and APTS [Hilgen et al., 1995; Abdul Aziz et al., 2003]. (o) corresponds to older and (y) corresponds to younger reversal boundary. Asterisks represent reversals that correspond to core breaks and which are hence less accurately determined.
Relative orientation between cores was not available but the magnetic inclinations predicted by an axial dipole field are $60^{\circ}$ at Site 608 , and thus steep enough to allow an unambiguous polarity determination, and the detection of directional excursions by changes in sign, regardless of the lack of declination control (Figure 3). The average inclination of the samples from Site 608 is $45.3 \pm 1.7^{\circ}$ for the $\mathrm{N}=293$ normal polarity set and $-43.2 \pm 2.0^{\circ}$ for the $\mathrm{N}=228$ reverse polarity set, which are perfectly antipodal within statistical errors but both too shallow for the sampling location presumably because of sedimentary inclination error [Celaya and Clement, 1988]. Nevertheless, the results suggest that coring deformation, storage, and sampling problems have not degraded the reliability of the magnetic signal to any appreciable extent.

\subsection{Chronology}

Plotting the inclination results against stratigraphic level in depth below seafloor shows that a large number (47) of polarity reversals have been registered (Figure 3 ). The conspicuously long normal magnetozone corresponding to Chron C $5 n .2 n$ is again easily identified in the middle part of the sequence. From this magnetozone, the correlation to the GPTS [Cande and Kent, 1992a, 1995] can be straightforwardly extended upwards and downwards, resulting in the recovery of the complete polarity sequence from $\mathrm{C} 5 \mathrm{Ar}$ to $\mathrm{C} 3 \mathrm{Br}$ (Figure 3). This implies that we have obtained a rather continuous (apart from several core breaks) polarity record from about 13 to $7.5 \mathrm{Ma}$. In addition, nine excursions have been identified which do not correspond to subchrons in the GPTS (Figure 3). None of these intervals are associated with core section breaks or biscuited material. Four of them are determined by only one or two samples and are hence not unambiguous, but the other five are ascertained by more than two samples. Following the cryptochron terminology of Cande and Kent [1992a, 1995], these candidate polarity zones are named C4r.2r-1, C4Ar.1r-1, C5n.2n-1, C5n.2n-2, C5n.2n-3, C5r.2r-1, C5r.2r2, C5r.3r-1 and C5An.2n-1 (Table 2).

The unequivocal correlation of the magnetic polarity stratigraphy of Site 608 to the GPTS establishes a more accurate chronology for the Middle to Late Miocene sediments and stratigraphy of the North Atlantic. The ages for all reversals of Site 608 (Table 1) are given according to the most recent GPTS [Cande and Kent, 1995] and to the Mediterranean based astronomical polarity time scale (APTS; [Hilgen et al., 1995; Abdul Aziz et al., 2003]). This allows an accurate estimation of the sediment accumulation rate at Site 608 (Figure 4). This sedimentation rate appears to be fairly constant throughout the Middle Miocene (13-10 Ma) with an average value of $2.3 \mathrm{~cm} / \mathrm{kyr}$, but decreases in the Late Miocene (10-7 Ma) to an average of $1.7 \mathrm{~cm} / \mathrm{kyr}$. Consequently, the position and dura- 


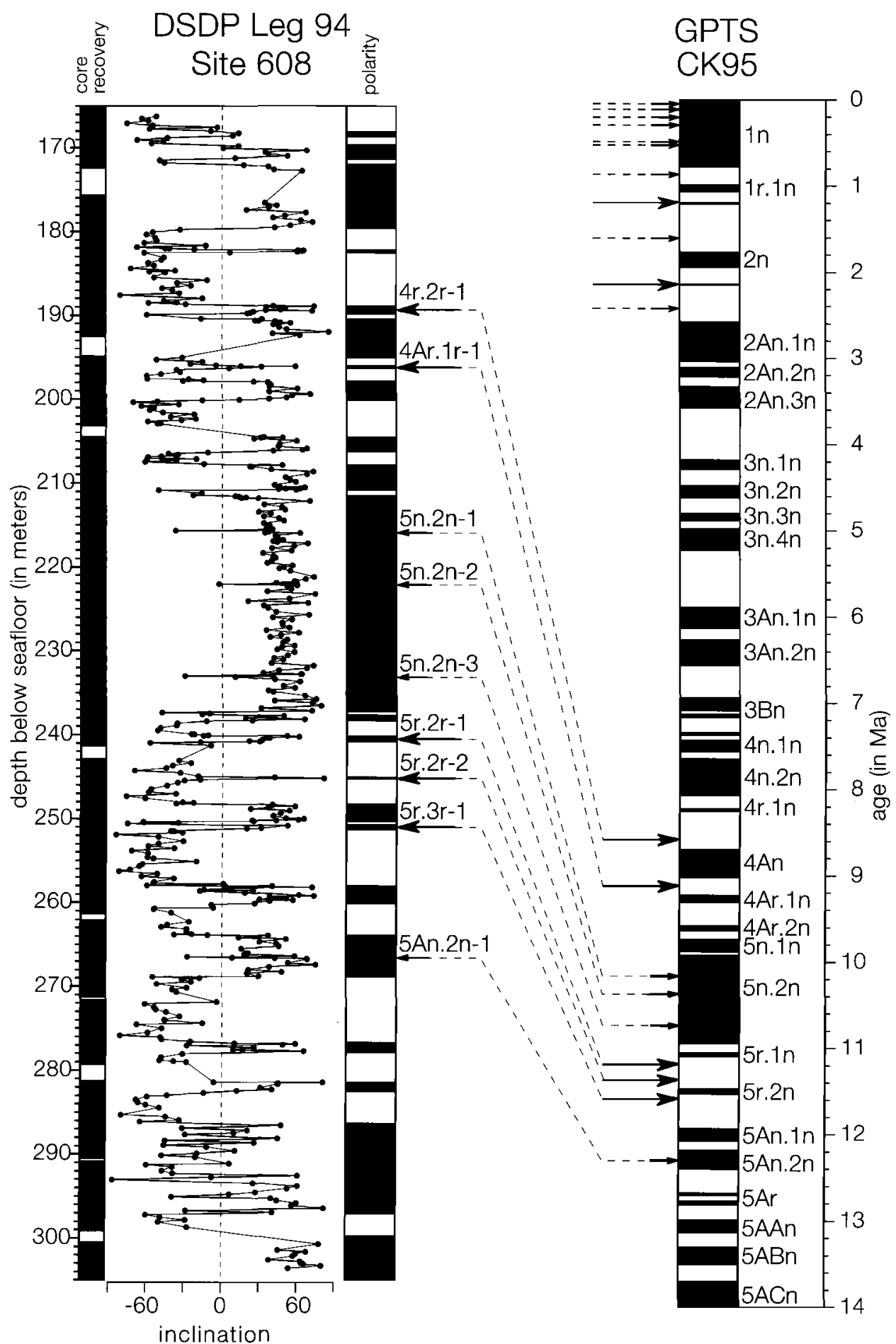

Figure 3. Correlation of the DSDP Site 608 magnetostratigraphy to the GPTS of Cande and Kent [1995]. Large (small) arrows indicate positions of short subchrons (excursions). 
Table 2. Position in meters below seafloor (mbsf) of the short-term polarity fluctuations in DSDP Site 608 and their relative position within the corresponding subchron of the GPTS

\begin{tabular}{|c|c|c|c|c|c|c|c|c|}
\hline \multirow{2}{*}{$\begin{array}{l}\text { Short-term } \\
\text { fluctuation }\end{array}$} & \multirow{2}{*}{$\begin{array}{l}\text { Depth (mbsf) } \\
\text { Site } 608\end{array}$} & \multirow{2}{*}{$\begin{array}{l}\text { Position } \\
\text { Site } 608\end{array}$} & \multicolumn{3}{|c|}{ Duration (in kyr) } & \multirow[b]{2}{*}{ Orera } & \multicolumn{2}{|r|}{ Name } \\
\hline & & & 608 & CK95 & 845 & & 1092 & \\
\hline C4r.2r-1 & $188.76-189.81$ & C4r.2r(0.92-0.79) & 61 & 16 & 44 & 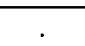 & 24 & $\mathrm{C} 4 \mathrm{r} .2 \mathrm{r}-1 \underline{\mathrm{n}}$ \\
\hline C4Ar.1r-1 & $196.00-196.28$ & C4Ar.1r(0.45-0.38) & 17 & --- & 29 & . & 13 & $\mathrm{C} 4 \mathrm{Ar} \cdot 1 \mathrm{r}-1 \underline{\mathrm{n}}$ \\
\hline C $5 n \cdot 2 n-1$ & $215.65-215.68$ & $C 5 n .2 n(0.16)$ & 1 & 8 & $\cdots$ & . & 3 & DIP \\
\hline C $5 n \cdot 2 n-2$ & $221.97-222.10$ & C $5 n .2 n(0.41)$ & 6 & 24 & $\cdots$ & . & 3 & DIP \\
\hline C $5 n \cdot 2 n-3$ & $232.89-233.02$ & C5n.2n(0.83) & 6 & 16 & --- & . & 5 & DIP \\
\hline C $5 r .2 r-1$ & $240.17-240.86$ & C5r.2r(0.25-0.18) & 31 & ---- & 26 & 26 & 38 & $\mathrm{C} 5 \mathrm{r} \cdot 2 \mathrm{r}-1 \mathbf{n}$ \\
\hline C5r.2r-2 & $245.02-245.27$ & C5r.2r(0.70-0.67) & 15 & ---- & $-\ldots$ & 15 & 5 & C5r.2r-2n \\
\hline C5r.3r-1 & $250.77-251.31$ & C5r.3r(0.13-0.06) & 25 & ---- & ---- & 9 & 6 & C5r.3r-1 $\underline{\mathbf{n}}$ \\
\hline C 5 An. $2 n-1$ & $266.44-266.50$ & C5An. $2 n(0.53-0.51)$ & 3 & $-\cdots$ & $<9$ & $?$ & . & DIP \\
\hline
\end{tabular}

Values are in fractional position from the younger end of the subchron. Duration for each event is in kiloyears as calculated from sedimentation rates (Site 608, Site 1092), seafloor spreading rates (GPTS), and astronomical forcing (Orera). Fluctuations that have an overall duration greater than 9-15 kyr qualify as short subchrons and are labeled as such with a suffix designing polarity. Features of less than $10 \mathrm{kyr}$ are interpreted to represent directional excursions associated in most cases with a decrease in paleointensity (DIP).

tion of the nine candidate subchrons that have been recorded as directional excursions can be determined from their average thickness and the average sedimentation rates of the abovementioned intervals (Table 2).

\subsection{Reliability of the Paleomagnetic Signal}

The four directional excursions that occur within normal polarity intervals (C5n.2n-1, C 5n.2n-2, C5n.2n-3, and C5An.2n-1) are all determined by a single specimen and hence are of relatively very short duration $(<6 \mathrm{kyr}$; Table 2$)$. The five new directional excursions that occur within reverse polarity intervals (C4r.2r-1, C4Ar.1r-1, C5r.2r-1, C5r.2r-2, and $\mathrm{C} 5 \mathrm{r} .3 \mathrm{r}-1$ ) are all determined by at least 3 samples but are inherently suspect as they may be related to a viscous component induced by the present day field. To validate the paleomagnetic signal, we have subjected selected samples covering all the individual directional excursions, as well as samples from the neighboring intervals of normal or reverse polarity, to isothermal remanent magnetization (IRM) component analyses. These experiments allow a diagnostic comparison between the magnetic carriers of the different intervals, which could be an indication for the reliability of the paleomagnetic signal. IRM acquisition curves were measured using a PM4 pulse magnetizer. The magnetic components are characterized by the saturation IRM (SIRM), the peak field at which half of the SIRM is reached $\left(\mathrm{B}_{1 / 2}\right)$, and the dispersion of the corresponding cumulative log-normal distribution according to the IRM component fitting method of [Kruiver et al., 2001].

A total of 18 samples have been selected for the IRM component analysis. All samples are dominated by a relatively low-coercivity component with a $B_{1 / 2}$ value of approximately $40-50 \mathrm{mT}$, which is compatible with magnetite or partially oxidized magnetite (Table 3). The results show that there is no significant difference in magnetic composition between samples from the directional excursions and from neighboring polarity zones (Table 3 ). This implies that the directional excursions are not simply explained by differences in lithology or lithology-related diagenetic processes, and that they thus probably reflect true variations of the geomagnetic field.

There is, however, a marked change in composition occurring in the section, which may be related to the change in sedimen-

Table 3. Results of IRM component analysis of selected samples of DSDP site 608 that straddle the short-term polarity fluctuations

\begin{tabular}{lclcccr}
\hline Sample & Depth & Small-term & \multicolumn{4}{c}{ Component 1 } \\
Code & (mbsf) & fluctuation & SIRM & B $_{1 / 2}$ & $\%$ & DP \\
\hline D21.3.085 & 189.15 & C4r.2r-1 & 190 & 53 & 77 & 0.26 \\
D21.4.014 & 189.94 & & 134 & 50 & 79 & 0.28 \\
D21.4.131 & 191.11 & & 142 & 50 & 75 & 0.28 \\
D22.1.034 & 195.24 & & 260 & 53 & 85 & 0.28 \\
D22.1.120 & 196.10 & C4Ar.1r-1 & 190 & 56 & 86 & 0.27 \\
D22.2.112 & 197.52 & & 146 & 51 & 80 & 0.27 \\
D24.2.005 & 215.65 & & 770 & 43 & 94 & 0.28 \\
D24.6.038 & 221.98 & C5n.2n-1 & 1920 & 44 & 85 & 0.24 \\
D25.7.027 & 232.97 & C5n.2n-2 & 1570 & 42 & 91 & 0.27 \\
D26.1.036 & 233.66 & & 1470 & 41 & 92 & 0.27 \\
D26.3.108 & 237.38 & & 3000 & 44 & 92 & 0.25 \\
D26.3.145 & 237.75 & C5r.2r-1 & 9700 & 43 & 89 & 0.27 \\
D27.1.077 & 243.67 & & 2520 & 40 & 90 & 0.25 \\
D27.2.079 & 245.19 & C5r.2r-2 & 1890 & 43 & 78 & 0.23 \\
D27.3.114 & 247.04 & & 3220 & 41 & 83 & 0.25 \\
D27.6.011 & 250.46 & & 2200 & 40 & 86 & 0.24 \\
D27.6.078 & 251.13 & C5r.3r-1 & 2320 & 40 & 83 & 0.23 \\
D27.6.109 & 251.44 & & 2170 & 38 & 85 & 0.24 \\
\hline
\end{tabular}

Values of the main component are given by Saturation IRM (SIRM) in $10^{3} \mathrm{~A} / \mathrm{m}$, the peak field at which half of the SIRM is reached $\left(\mathrm{B}_{1 / 2}\right)$ in $\mathrm{mT}$, percentage of the main component $(\%)$, and the dispersion parameter (DP). 


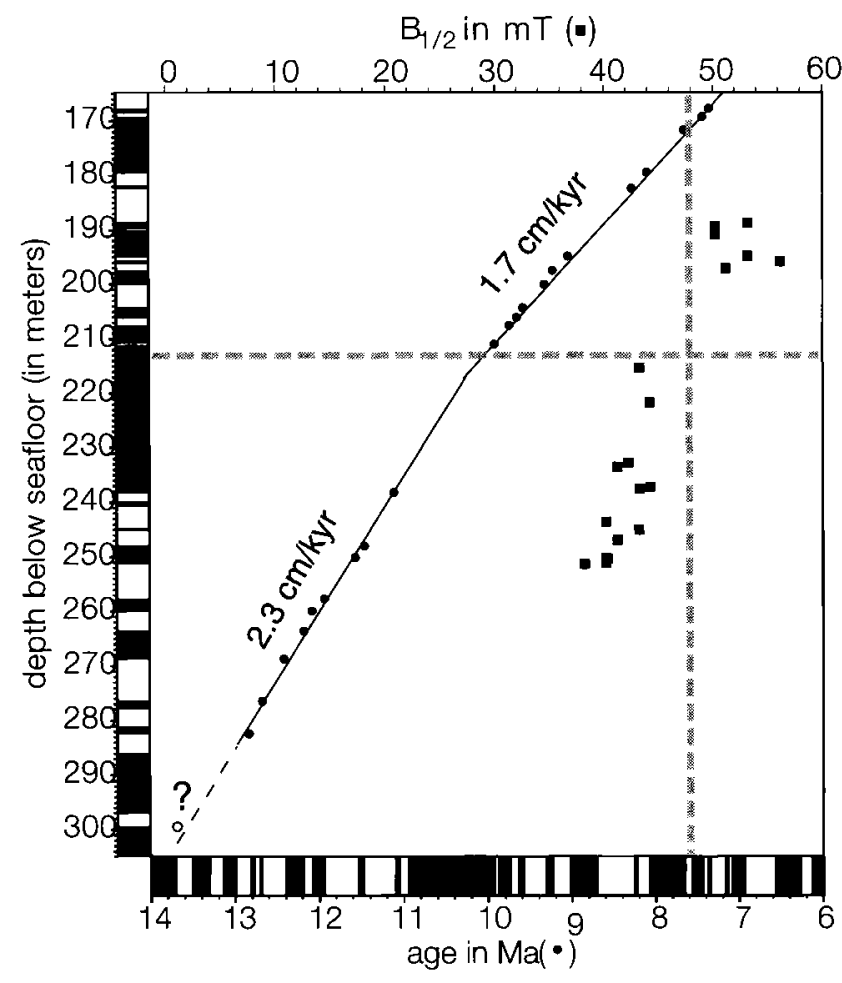

Figure 4. Polarity column for DSDP Site 608 as a function of depth (mbsf) versus age (Ma) in CK95, displayed by solid dots. Note the evident change in sedimentation rate from $2.3 \mathrm{~cm} / \mathrm{kyr}$ in the lower part to $1.7 \mathrm{kyr}$ in the upper part of the sequence. Squares represent $B_{1 / 2}$ values in (mT) of the dominant magnetic component in selected samples for IRM analysis. A change in $B_{1 / 2}$ values of about $40 \mathrm{mT}$ to values higher than $50 \mathrm{mT}$ roughly corresponds to the change in sedimentation rate.

tation rate at the top of C5n.2n at approximately $211 \mathrm{mbsf}$ (Figure 4). Above this level, the $B_{1 / 2}$ values range between 50 and $56 \mathrm{mT}$, compatible with single domain magnetite. The dispersion parameters suggest a detrital origin for this component because they are generally too high for a biogenic origin [Kruiver and Passier, 2001]. In the lower part of the sequence, the $B_{1 / 2}$ values are around $40 \mathrm{mT}$ whereas SIRM values are an order of magnitude higher. This implies that the magnetic component may suffer from viscous resetting as the lower part of the grain size distribution tails to the super-paramagnetic grain size range. The IRM results are in good agreement with the AFdemagnetization results, which show a very stable component in the upper part of the sequence and commonly a much larger secondary component in the lower part (Figure 2).

\section{COMPARISON WITH OTHER RECORDS}

Many of the short-term fluctuations in the geomagnetic field, either recorded as tiny wiggles in marine magnetic anomalies or as excursions in direction in sedimentary geological records, have an uncertain origin. Consequently, the age, origin and nature of any short-term fluctuation needs to be confirmed by other records from different parts of the world, so that its status can be ascertained as simply a directional excursion (perhaps accompanied by a decrease in paleointensity) or a short polarity subchron. Although there are not yet many reliable paleomagnetic studies of sufficiently highresolution from the Middle to Late Miocene time interval available, several studies have revealed the existence of directional excursions or subchrons in this time interval.

Detailed studies of the marine magnetic anomaly profiles of the ocean floor revealed several small-scale fluctuations in the Middle to Late Miocene time interval [Blakely, 1974; Cande and LaBrecque, 1974]. Four of these 'tiny wiggles' have been nominated as cryptochrons in CK92 (Table 2) and their duration has been calculated from sea floor spreading rates (C4r.2r-1 of $16 \mathrm{kyr}, \mathrm{C} 5 \mathrm{n} .2 \mathrm{n}-1$ of $8 \mathrm{kyr}, \mathrm{C} 5 \mathrm{n} .2 \mathrm{n}-2$ of 24 kyr and C $5 n .2 n-3$ of $16 \mathrm{kyr}$ ). The three cryptochrons of $C 5 n$ had previously also been recognized from magnetic profiles of the northeast Pacific by Blakely [1974] who suggested that they correspond to short polarity subchrons and that they should be incorporated as such in the GPTS. In contrast to this, a thorough re-study of the C $5 n$ interval of the sea-surface and near-bottom profiles in the North and South Pacific suggested that the tiny wiggles in C5n most likely represent intensity fluctuations [Bowers et al., 2001; Bowles et al., 2003]. Anomaly data alone, however, cannot uniquely determine whether tiny wiggles in the anomaly profiles represent either short subchrons or paleointensity variations. Consequently, data from sedimentary sequences provide crucial information to determine the exact nature of each cryptochron.

The paleomagnetic record from the low latitude ODP Site 845 in the Equatorial Pacific (Figure 1) is perhaps one of the most valuable examples of a continuous mid-Miocene to midPliocene magnetostratigraphic record (Figure 5; [Schneider, 1995; Schneider et al., 1997]). The Miocene magnetostratigraphy of this site was generated partly from pass-through magnetometer measurements and partly by using discrete samples [Schneider, 1995]. Here, only the declination provided useful results, since inclination changes alone were rarely indicative of polarity because of the low site latitude $\left(10^{\circ} \mathrm{N}\right)$. The combined magnetostratigraphic records from Holes $845 \mathrm{~A}$ and $845 \mathrm{~B}$ documented five short putative polarity intervals in the Middle to Late Miocene epoch (Figure 5). Only one of these events corresponds to a poorly defined tiny wiggle in the marine magnetic anomaly record, a cryptochron (C4r.2r-1) that is included in CK92. The three other short events (C4r.1r-1, C4Ar.1r-1, C5r.2r-1) were previously not identified. Correlation of the Site 845 magnetostratigraphy to the Site 608 record is straightforward and shows that three 

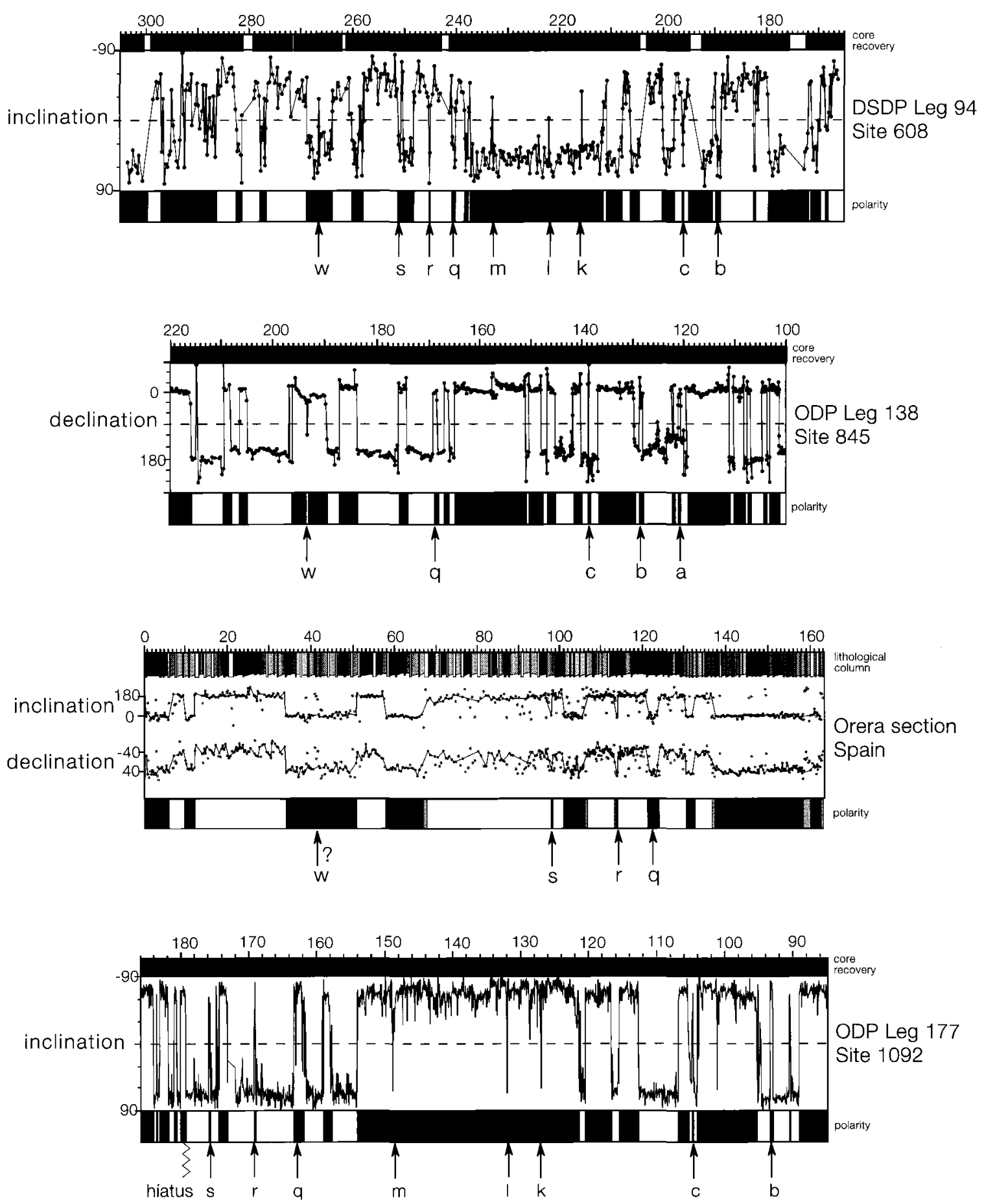

Figure 5. Comparison of the magnetostratigraphic records in local thickness units (meters) of DSDP Site 608, ODP Site 845 [Schneider et al., 1997], the Orera Composite Section [Abdul Aziz et al., 2000] and ODP Site 1092 (with adjustment of a revised composite depth section) [Evans et al.,2004] showing that all short-term poiarity fluctuations in Site 608 have been recorded elsewhere. $\mathbf{a}=\mathrm{C} 4 \mathrm{r} .1 \mathrm{r}-1, \mathrm{~b}=\mathrm{C} 4 \mathrm{r} \cdot 2 \mathrm{r}-1 \mathrm{n}, \mathrm{c}=\mathrm{C} 4 \mathrm{Ar} \cdot 1 \mathrm{r}-1 \mathrm{n}, \mathrm{k}=\mathrm{C} 5 \mathrm{n} \cdot 2 \mathrm{n}-1, \mathrm{l}=\mathrm{C} 5 \mathrm{n} \cdot 2 \mathrm{n}-2, \mathrm{~m}=\mathrm{C} 5 \mathrm{n} \cdot 2 \mathrm{n}-3, \mathrm{q}=\mathrm{C} 5 \mathrm{r} \cdot 2 \mathrm{r}-$ $1, \mathrm{r}=\mathrm{C} 5 \mathrm{r} \cdot 2 \mathrm{r}-2, \mathrm{~s}=\mathrm{C} 5 \mathrm{r} \cdot 3 \mathrm{r}-1$, and $\mathrm{w}=\mathrm{C} 5 \mathrm{An} \cdot 2 \mathrm{n}-1$. In the Orera Composite Section, the black signal line connects only the

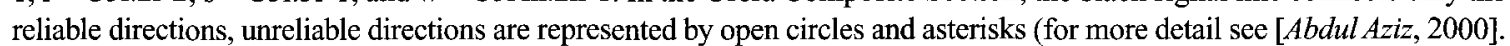


of these short events (C4r.2r-1, C4Ar.1r-1 and C5r.2r-1) have been registered in both sites (Figure 5). The fourth event (C4r.1r-1) is not recognized in Site 608. By contrast, there are no indications in Site 845 of the three cryptochrons within C5n (C5n.2n-1, C5n.2n-2 and C5n.2n-3), neither of the two additional ones in $\mathrm{C} 5 \mathrm{r}$ (C5r.2r-2 and C5r.3r-1). There is, however, a clear indication of a very short directional excursion within C5An.2n, which exactly correlates to our C5An.2n-1 event. This interval was not mentioned in the original interpretation by Schneider [1995]. Relative paleointensity studies of the intervals spanning the cryptochrons showed that C5r.2r1 reflected a full normal polarity interval with distinct intensity recovery between the bounding pair of reversals, while intensity recovery was not seen for $\mathrm{C} 4 \mathrm{r} .1 \mathrm{r}-1, \mathrm{C} 4 \mathrm{r} .2 \mathrm{r}-1$, or C4Ar.1r-1 [Schneider, 1995]. Consequently, he only considered C5r.2r-1 as a 'true' subchron and calculated its duration (26 kyr) from thickness and sedimentation rate. We have, however, calculated the duration for the other short intervals as well to allow a more detailed comparison between the different records. Durations of $44 \mathrm{kyr}$ for $\mathrm{C} 4 \mathrm{r} .2 \mathrm{r}-1(75 \mathrm{~cm})$ and of $29 \mathrm{kyr}$ for C4Ar.1 $1 \mathrm{r}-1(50 \mathrm{~cm})$ have been derived by applying the ages of CK95 to the most evident magnetic reversals (Table 2). The interval corresponding to C5An.2n-1 is only determined by one sample (sampling resolution of $10-15 \mathrm{~cm}$ ), which suggests that it should be less than $9 \mathrm{kyr}$ in duration.

The continental sediments of the Orera Composite Section of the Calatayud Basin in Spain (Figure 1) provide another reliable and detailed record of the time interval ranging from 10.6 to 13 Ma (Figure 5; [Abdul Aziz et al., 2000]). This section was sampled with a resolution of approximately $5 \mathrm{kyr}$ for the construction of an astronomical time scale for the continental realm, because of its very marked sedimentary cyclicity and its good paleomagnetic signal [Abdul Aziz et al., 2003]. The detailed magnetostratigraphic record of the Orera Composite Section showed three short normal polarity intervals that had not been registered in CK92. Detailed re-sampling and additional paleomagnetic, rock magnetic and geochemical analyses of these three intervals showed that they have a geomagnetic origin, and are not related to diagenetic or other sedimentary artifacts [Abdul Aziz, 2001; Abdul Aziz and Langereis, this volume]. The youngest of the three intervals corresponds to C5r.2r-1 of Schneider [1995], the older two were previously not determined and have been named $\mathrm{C} 5 \mathrm{r} .2 \mathrm{r}-2$ and C5r.3r-1 [Abdul Aziz, 2001; Abdul Aziz and Langereis, this volume]. Correlation to the Site 608 magnetostratigraphy shows that all these normal polarity intervals in C5r have been documented in the two records. The reverse polarity interval in C5An.2n was not noticed in the Orera Composite Section, although several levels showed reverse directions at its expected position (Figure 5). These directions were considered unreliable in the earlier interpretation because they corre- spond to components of very weak intensity [ $A b d u l$ Aziz et al., 2000], but this interval certainly warrants a more detailed reinvestigation. The duration of the three new normal polarity intervals in $\mathrm{C} 5 \mathrm{r}$ has been established from the number of sedimentary cycles, which were proven to be related to the astronomical cycle of precession with average periodicity of about 21.7 kyr [Abdul Aziz et al., 2003]. This resulted in durations of $26 \mathrm{kyr}$ for C5r.2r-1, $15 \mathrm{kyr}$ for C5r.2r-2 and $9 \mathrm{kyr}$ for C5r.3r-1 (Table 2).

Another excellent Upper Miocene paleomagnetic record was published recently from ODP Site 1092 (Figure 1), located in the sub-Antarctic South Atlantic [Evans and Channell, 2003]. The magnetostratigraphy for this site was obtained from u-channel samples of the composite stratigraphic section (Figure 5). The complete stratigraphic record of Site 1092, after adjustment of a revised composite depth section [Evans et al., 2004], clearly revealed evidence for changes in directions corresponding to C4r.2r-1 and to the three cryptochrons of C $5 \mathrm{n} .2 \mathrm{n}$ (Figure 5). In addition, the inclination record shows clear indications for a short normal interval at the stratigraphic position where C4Ar.1r-1 is expected, although not interpreted as such by Evans and Channell [2003]. The revised composite depth section of Site 1092 furthermore seems to favor a correlation of the lower part of the record different than presented by Evans and Channell [2003]. Biostratigraphic data from diatoms suggests the presence of a hiatus of approximately $800 \mathrm{kyr}$ at a level of 178.83 meters composite depth [Censarek and Gersonde, 2002]. The interval between this hiatus and the base of C $5 n .2 n$ matches the polarity pattern of the Orera Composite Section and the Site 608 record (Figure 5). This different correlation implies that the three additional directional excursions in C5r (C5r.2r-1, C5r.2r-2 and C5r.3r-1) have also been recorded at 1092, which have durations of $38 \mathrm{kyr}(144 \mathrm{~cm}), 5 \mathrm{kyr}(19$ $\mathrm{cm})$ and $6 \mathrm{kyr}(21 \mathrm{~cm})$, respectively (Table 2$)$.

Sediments from ODP Site 887 in the North Pacific are also known for their excellent magnetostratigraphy, in which C5n could also be unambiguously recognized [Weeks et al., 1995]. Shipboard inclination data from Site 887 Hole $C$ show that two short polarity intervals have been recorded that correspond to $\mathrm{C} 4 \mathrm{r} .2 \mathrm{r}-1$ and $\mathrm{C} 5 \mathrm{r} .2 \mathrm{r}-1$. There appears to be no indication for the other two normal polarity intervals in chron $\mathrm{C} 5 \mathrm{r}$ seen in Site 608, Site 1092 and Orera, nor for the cryptochrons in C5n. A detailed study of the relative paleointensity record from this site, compared with the deep tow anomaly records of [Bowers et al., 2001], has led to the conclusions that the tiny wiggles in C5n are most likely paleointensity variations, and if reverse polarity intervals exist in $\mathrm{C} 5 \mathrm{n}$, that they are likely to be less than $5 \mathrm{kyr}$ in duration [Bowles et al., 2003].

The paleomagnetic records recovered from ODP Site 884 in the North Pacific also comprise the entire C5n interval 
[Roberts and Lewin-Harris, 2000; Weeks et al., 1995]. Here, relative paleointensity data suggested that at two putative short polarity intervals the geomagnetic field collapsed at the polarity reversals and recovered to higher intensities within the short reverse polarity zones. This led to the conclusion that these two directional excursions within $\mathrm{C} 5 \mathrm{n}$ represent real subchrons with estimated durations of $26 \mathrm{kyr}$ and $28 \mathrm{kyr}$, respectively [Roberts and Lewin-Harris, 2000]. The magnetostratigraphic correlations of Site 884 , however, must be qualified as somewhat ambiguous [Bowles et al., 2003; Evans and Channell, 2003]. Indeed there appear to exist dramatic changes in sedimentation rate at this site, corresponding exactly to the C5n interval. Although Roberts and Lewin-Harris [2000] implied that the sedimentation rates were relatively uniform over long periods of time and averaged about $3.6 \mathrm{~cm} / \mathrm{kyr}$ between 12.4 and $7 \mathrm{Ma}$, calculation of the sedimentation rates according to their magnetostratigraphic correlation shows instead that there were significant changes, from $2.0 \mathrm{~cm} / \mathrm{kyr}$ in C5n.2n (21 m; $1029 \mathrm{kyr})$ to $10.7 \mathrm{~cm} / \mathrm{kyr}$ in C5n. $1 \mathrm{n}$ ( $15 \mathrm{~m}$; $140 \mathrm{kyr}$ ). This suggests that the conclusions derived from the Site 884 record must be treated with caution.

\section{DISCUSSION}

Short-term polarity fluctuations in the geomagnetic field have been registered in many portions of the geological time scale, but in numerous cases serious debate is related to whether they correspond to short polarity subchrons or to directional excursions that are associated with a decrease in paleointensity (DIP). The classic definition of an excursion implies a short-term departure of the Virtual Geomagnetic Pole (VGP) that is considerably larger than that seen in secular variation (e.g., [Langereis et al., 1997; Merrill et al, 1998]). Excursions are most likely events in which the geomagnetic field reverses in the liquid outer core but not in the solid inner core, which implies that expressions of excursions may not be equally significant around the globe [Gubbins, 1999]. By contrast, short polarity subchrons are characterized by an interval of opposite polarity, bounded by a pair of geomagnetic polarity reversals. Short-period polarity intervals presumably require the inner core to have reversed its polarity [Gubbins, 1999]. The magnetic field in the solid inner core can only change by diffusion, which would result in approximately 3-5 kyr for a full polarity reversal to take place [Hollerbach and Jones, 1993], and as such implying a minimum duration of 6-10 kyr for just the bounding reversals of a polarity subchron.

Duration may thus be a useful criterion to help distinguish a DIP-related excursion from a short polarity subchron. For example, Cande and Kent [1992a, 1992b] relegated 'tiny wiggles' whose apparent duration was less than $30 \mathrm{kyr}$ as cryp- tochrons because it was ambiguous whether the origin of these geomagnetic features recorded in the magnetic anomaly patterns was due to short intervals of opposite polarity or simply to DIPs of the geomagnetic field. If we follow the arguments of Gubbins [1999], only features having an overall duration greater than 9-15 kyr would thus qualify as short polarity subchrons whereas features less than about $10 \mathrm{kyr}$ would more likely represent DIP-related excursions. On this basis, C4r.2r1n, C4A.1r-1n, C5r.2r-1n, C5r.2r-2n, and C5r.3r-1n in Site 608 , with supporting data described above from Site 845, Site 1092, and/or the Orera Composite Section, have been elevated to polarity subchrons (and are labeled as such with a suffix designating polarity) whereas C $5 n .2 n-1, C 5 n .2 n-2$, C5n.2n-3 and C5An.2n-1, with apparent durations less than $10 \mathrm{kyr}$, would be better described as directional excursions (Table 2 and 4). Although all these polarity fluctuations have been observed in more than one record, the age and duration of most of them still awaits an accurate and reliable dating, preferably by astronomical calibration techniques. Apart from the three short polarity subchrons in the Orera Composite section, all other Middle to Late Miocene events have so far only been dated by assuming a uniform sedimentation rate. This may sometimes result in incorrect age and duration estimates, which can have significant consequences for global correlations and if we also accept duration as a useful criterion to help distinguish between excursions and short polarity subchrons.

The ongoing debate whether tiny wiggles represent shortperiod geomagnetic polarity intervals or relate to decreases in geomagnetic intensity has thus not yet been fully resolved, although we believe that the short duration of the features within C5n.2n at Site 608 and their inconsistent expression from site to site makes them more likely to reflect DIP-related excursions of the geomagnetic field. In addition, the numer-

Table 4. Position in meters below seafloor (mbsf) of the magnetic reversals of the short subchrons in DSDP site 608, with ages (Ma) according to the GPTS [Cande and Kent, 1995]

\begin{tabular}{lll}
\hline $\begin{array}{l}\text { Short } \\
\text { subchron }\end{array}$ & $\begin{array}{l}\text { Site 608 } \\
\text { depth (mbsf) }\end{array}$ & $\begin{array}{l}\text { GPTS } \\
\text { age }\end{array}$ \\
\hline C4r.2r-1n (y) & $188.84-188.67$ & 8.606 \\
C4r.2r-1n (o) & $189.94-189.68$ & 8.664 \\
C4Ar.1r-1n (y) & $196.05-195.94$ & 9.097 \\
C4Ar.1r-1n(o) & $196.45-196.10$ & 9.117 \\
C5r.2r-1n (y) & $240.23-240.11$ & 11.167 \\
C5r.2r-1n (o) & $240.88-240.83$ & 11.193 \\
C5r.2r-2n (y) & $245.08-244.95$ & 11.352 \\
C5r.2r-2n (o) & $245.32-245.21$ & 11.363 \\
C5r.3r-1n (y) & $250.83-250.71$ & 11.555 \\
C5r.3r-1n (o) & $251.44-251.17$ & 11.584 \\
\hline
\end{tabular}


ous (18) cryptochrons in the Oligocene anomaly record have so far not been resolved in the sedimentary archives. Channell et al. [2003] recognize one new excursion in the Oligocene (C7Ar-1) and one in the early Miocene (C5Dr-1), but both of them do not correspond to a cryptochron of CK92. Other detailed paleomagnetic studies on Oligocene sediments did not reveal any excursions at all, which lead to the conclusion that the Oligocene tiny wiggles correspond to DIPs, which may have been accompanied by directional excursions [Lowrie and Lanci, 1994; Lanci and Lowrie, 1997; Tauxe and Hartl, 1997]. It is possible, however, that these Oligocene records suffer from diagenetic processes which might have obscured the geomagnetic signal, especially because the sedimentation rates of these sites are relatively low [Roberts and LewinHarris, 2000]. This confirms the need for detailed and independent paleomagnetic analyses corresponding to each tiny wiggle in the ocean floor anomaly pattern and for each shortterm polarity fluctuation in the sedimentary record.

The paleomagnetic data of late Neogene sediments furthermore suggest that the occurrence of short-term polarity fluctuations is indeed non-uniformly distributed, with numerous excursions and two short subchrons (Cobb Mountain and Reunion-1) in the Brunhes-Matuyama interval, an interval with no evidence for excursions in the latest Miocene to early Pliocene, and at least the nine short events (of which five can be considered as short subchrons) in the early Late Miocene interval (Figure 3). It remains uncertain whether this apparent non-uniform occurrence of short-term polarity fluctuations is related to geomagnetic field behavior or to registration problems of the paleomagnetic signal. For instance, the CK92 time scale used magnetic anomaly profiles from the relatively slow-spreading NE Pacific for the interval corresponding to C5n and C5r [Cande and Kent, 1992a]. These profiles only have a marginal resolution in which short anomaly fluctuations are not easily recognized. Marine magnetic anomaly profiles from the central Pacific and Nazca plates have higher resolution and already revealed the existence of subchron C5r.2r-1n [Abdul Aziz et al., 2003]. Registration problems in the magnetic anomaly patterns may thus be an explanation for the discovery of the new short polarity fluctuations in the Middle to Late Miocene time interval.

By contrast, the absence of short-term polarity fluctuations in the latest Miocene-early Pliocene is not easily explained by registration problems in the marine magnetic anomalies. Detailed anomaly data from various fast-spreading ridges were combined for the Pliocene, while reliable profiles from the relatively fast and uniformly spreading Chile Ridge and East Pacific Rise were used for the Late Miocene time scale [Cande and Kent; 1992a]. Many of the paleomagnetic records, however, show data of inferior quality during this time interval, especially during the Late Miocene. The Mediterranean sections all suffered from the Messinian Salinity Crisis, which resulted in deposition of sediments that are less suitable for magnetostratigraphy [Krijgsman et al., 1995, 1999]. This major paleoceanographic event may also have had its influence on the Atlantic Ocean sediments as the magnetic signal in the Site 608 record could not be properly recovered from the Messinian interval [Clement and Robinson, 1986]. In addition, the Messinian to early Pliocene of Site 1092 is represented by an interval of uninterpretable polarity stratigraphy [Evans and Channell, 2003], while also the Pliocene of Site 884 gives correlation problems. Consequently, this time interval still awaits more high-resolution, high-quality records, preferably accompanied by paleointensity data.

\section{CONCLUSIONS}

A detailed paleomagnetic resampling and remeasuring of DSDP Site 608 of the North Atlantic resulted in the registration of a complete magnetostratigraphic record from 13 to 7.5 Ma. In addition, nine short-term polarity fluctuations have been identified which do not correspond to subchrons in the GPTS. IRM component analysis show that there is no significant difference in magnetic composition between samples from the excursions and from neighboring polarity zones, implying that the polarity fluctuations reflect true variations of the past geomagnetic field. Comparison to other records show that all nine events have also been recognized in other sites from different part of the world.

If we follow the arguments of Gubbins [1999] and assume that short polarity subchrons should have a minimum overall duration of more than 9-15 kyr, five new subchrons are registered in the early Late Miocene record: C4r.2r-1n, C4Ar.1r-1n, C5r.2r$1 \mathrm{n}, \mathrm{C} 5 \mathrm{r} .2 \mathrm{r}-2 \mathrm{n}$, and C5r.3r-1n. In addition, the three polarity fluctuations within C5n (C5n.2n-1, C5n.2n-2, C5n.2n-3) and the interval termed C5An. $2 n-1$ in the paleomagnetic record of Site 608 qualify better as DIP-related excursions. The addition of just a few new subchrons makes the distribution of polarity interval lengths conform closer to a Poisson model wherein the probability of a reversal stays constant and does not depend on a previous occurrence [Lowrie and Kent, this volume].

Our results imply that the occurrence of short-term polarity fluctuations in the geomagnetic field is non-uniformly distributed through time, with several excursions and subchrons in the Brunhes-Matuyama (2.5-0 Myr) and early Late Miocene (12.5-8 Myr) intervals and none in the late Miocene to early Pliocene (8-2.5 Myr). Resolution problems in the marine magnetic anomaly profiles of the early Late Miocene time interval, however, may also help explain the discovery of new subchrons in magnetostratigraphic records in this time interval. In addition, poor quality paleomagnetic records could account for the apparent absence of short-term polarity fluctuations in 
the latest Miocene-Early Pliocene. Studies of the Oligocene, which is the next interval known for the common occurrence of cryptochrons, have not confirmed the existence of polarity subchrons. Instead, they suggested that these tiny wiggles most likely correspond to DIPs of the geomagnetic field. Consequently, it is uncertain if the observed non-uniform occurrence of short-term polarity fluctuations is truly related to specific behavior of the geodynamo. Nevertheless it remains interesting to notice that directional excursions have so far not been observed in the latest Miocene to early Pliocene records.

Acknowledgments. We thank Gar Esmay for his help with sampling of the Site 608 cores, Dave Schneider and Helen Evans for providing us with the data of ODP Site 845 and the adjusted record of ODP Site 1092, and Cor Langereis, Mark Dekkers and Hayfaa Abdul Aziz for fruitful discussions on an earlier version of the manuscript. We also acknowledge the constructive comments of Jim Channell and two anonymous reviewers. WK acknowledges financial support from the Netherlands Research Centre for Integrated Solid Earth Sciences (ISES) for his stay at LDEO. The work was carried out under the program of the Vening Meinesz Research School of Geodynamics. It is Lamont-Doherty Earth Observatory contribution \#6553.

\section{REFERENCES}

Abdul Aziz, H., Astronomical forcing in continental sediments. An integrated stratigraphic study of Miocene deposits from the Calatayud and Teruel basins, NE Spain, Geol.Ultraiectina, 207, 191 pp., 2001.

Abdul Aziz, H., F. Hilgen, W. Krijgsman, E. Sanz, and J. P. Calvo, Astronomical forcing of sedimentary cycles in the middle to late Miocene continental Calatayud Basin (NE Spain), Earth Planet. Sci. Lett., I77, 9-22, 2000.

Abdul Aziz, H., W. Krijgsman, F. J. Hilgen, D. S. Wilson, and J. P. Calvo, An astronomical polarity timescale for the late middle Miocene based on cyclic continental sequences, J. Geophys. Res., 108, EPM 5/1-16 doi: 10.1029/2002JB00181, 2003.

Abdul Aziz, H., and C. G. Langereis, Astronomical tuning and duration of three new subchrons (C5r.2r-1n, C5r.2r-2n and C5r.3r-1n) recorded in a Middle Miocene continental sequence from NE Spain, this volume, pp. 141-160

Blakely, R. J., Geomagnetic reversals and crustal spreading rates during the Miocene, J. Geophys. Res., 79, 2979-2985, 1974.

Bowers, N. E., S. C. Cande, J. S. Gee, J. A. Hildebrand, and R. L. Parker, Fluctuations of the paleomagnetic field during chron $\mathrm{C} 5$ as recorded in near-bottom marine magnetic anomaly data, $J$. Geophys. Res., 106, 26,379-26,396, 2001.

Bowles, J., L. Tauxe, J. Gee, D. McMillan, and S. C. Cande, The source of tiny wiggles in Chron C5: A comparison of sedimentary relative intensity and marine magnetic anomalies, Geochem. Geophys. Geosyst., 4(6), 1049, doi:10.1029/2002 GC000489, 2003.
Cande, S. C., and D. V. Kent, A new geomagnetic polarity time scale for the Late Cretaceous and Cenozoic, J. Geophys. Res., 97, 13,917-13,951, 1992a.

Cande, S. C., and D. V. Kent, Ultrahigh resolution marine magnetic anomaly profiles: A record of continuous paleointensity variations?, I. Geophys. Res., 97, 15,075-15,083, 1992b.

Cande, S. C., and D. V. Kent, Revised calibration of the geomagnetic polarity time scale for the Late Cretaceous and Cenozoic, $J$. Geophys. Res., 100, 6093-6095, 1995.

Cande, S. C., and J. L. LaBrecque, Behaviour of the Earth's paleomagnetic field from small-scale marine magnetic anomalies, Nature, 247, 26 28, 1974.

Celaya, M., and B. M. Clement, Inclination shallowing in deep-sea sediments from the North Atlantic, Geophys. Res. Lett., 15, 52-55, 1988.

Censarek, B., and R. Gersonde, Miocene diatom biostratigraphy at ODP sites 689, 690, 1088, 1092 (Atlantic sector of the Southern Ocean), Marine Micropal., 45, 309-356, 2002.

Channell, J. E. T., A. Mazaud, P. Sullivan, S. Turner, and M. E. Raymo, Geomagnetic excursions and paleointensities in the 0.9-2.15 Ma interval of the Matuyama Chron at ODP Site 983 and 984 (Iceland Basin), J. Geophys. Res., 107 B(6), doi: 10.1029/2001JB000491, 2002.

Channell, J. E. T., S. Galeotti, E. E. Martin, K. Billups, H. D. Scher, and J. S. Stoner, Eocene to Miocene magnetostratigraphy, biostratigraphy, and chemostratigraphy at ODP Site 1090 (sub-Antarctic South Atlantic), GSA Bull., 115, 2003.

Clement, B. M., and D. V. Kent, Short polarity intervals within the Matuyama: transitional field records from hydraulic piston cored sediments from the North Atlantic, Earth Planet. Sci. Lett., 81, 253-264, 1987.

Clement, B. M., and F. Robinson, The magnetostratigraphy of Leg 94 sediments, 635-650 pp., U.S. Government Printing Office, Washington, D.C., 1986.

Evans, H. F., and J. E. T. Channell, Upper Miocene magnetic stratigraphy at ODP site 1092 (sub-Antarctic South Atlantic): recognition of 'cryptochrons' in C5n.2n, Geophys. J. Int., I53, 483-496, 2003.

Evans, H. F., Westerhold, T., and J.E. T. Channell, Revised composite depth section has implications for Upper Miocene "cryptochrons", Geophys. J. Int., 156, 195-199, 2004.

Garcés, M., J. Agustí, L. Cabrera, and J. M. Parés, Magnetostratigraphy of the Vallesian (late Miocene) in the Vallès-Penedès Basin (northeast Spain), Earth Planet. Sci. Lett., 142, 381-396, 1996.

Garcés, M., W. Krijgsman, and J. Agustí, Chronostratigraphic framework and evolution of the Fortuna Basin (Eastern Betics) since the Late Miocene, Basin Research, 13(2), 199-216, 2001.

Gartner, S., Miocene nannofossil chronology in the North Atlantic, DSDP Site 608, Marine Micropal., 18, 307-313, 1992.

Gubbins, D., The distinction between geomagnetic excursions and reversals, Geophys. J. Int. -Fast Track, 137, F1-F3, 1999.

Hilgen, F. J., W. Krijgsman, C. G. Langereis, L. J. Lourens, A. Santarelli, and W. J. Zachariasse, Extending the astronomical 
(polarity) time scale into the Miocene, Earth Planet. Sci. Lett., 136, 495-510, 1995.

Hollerbach, R, and C. A. Jones, Influence of the Earth's inner core on geomagnetic fluctuations and reversals, Nature, 365, 541-543, 1993.

Krijgsman, W., F. J. Hilgen, C. G. Langereis, A. Santarelli, and W. J. Zachariasse, Late Miocene magnetostratigraphy, biostratigraphy and cyclostratigraphy in the Mediterranean, Earth Planet. Sci. Lett., 136, 475-494, 1995.

Krijgsman, W., F. J. Hilgen, I. Raffi, F. J. Sierro, and D. S. Wilson, Chronology, causes and progression of the Messinian salinity crisis, Nature, 400, 652-655, 1999.

Kruiver, P. P., M. J. Dekkers, and D. Heslop, Quantification of magnetic coercivity components by the analysis of acquisition curves of isothermal remanent magnetisation, Earth Planet. Sci. Lett., 189, 269-276, 2001.

Kruiver, P. P., and H. F. Passier, Coercivity analysis of magnetic phases in sapropel $\mathrm{S} 1$ related to variations in redox conditions, including an investigation of the S-ratio, Geochem. Geophys. Geosyst, doi:2001GC000181, 2001.

Lanci, L., and W. Lowrie, Magnetostratigraphic evidence that 'tiny wiggles' in the oceanic magnetic anomaliy record represent geomagnetic paleointensity variations, Earth Planet. Sci. Lett., 148, 581-592, 1997.

Langereis, C. G., M. J. Dekkers, G. J. de Lange, M. Paterne, and P. J. M. van Santvoort, Magnetostratigraphy and astronomical calibration of the last 1.1 Myr from an eastern Mediterranean piston core and dating of short events in the Brunhes, Geophys. J. Int., 129, 75-94, 1997.

Langereis, C. G., and F. J. Hilgen, The Rosello composite: a Mediterranean and global reference section for the Early to early Late Pliocene, Earth Planet. Sci. Lett., 104, 211-225, 1991.

Li, J.-J., X.-M. Fang, R. Van der Voo, J.-J. Zhu, C. MacNiocaill, Y. Ono, B.-T. Pan, W. Zhong, J.-L. Wang, T. Sasaki, Y.-T. Zhang, J.-X. Cao, S.-C. Kang, and J.-M. Wang, Magnetostratigraphic dating of river terraces: Rapid and intermittent incision by the Yellow River of the northeastern margin of the Tibetan Plateau during the Quaternary, J. Geophys. Res., 102, 10,121-10,132, 1997a.

Li, J. J., X. M. Fang, R. V.d. Voo, J .J. Zhu, C. MacNiocaill, J. X. Cao, W. Zhong, H. L. Chen, J. L. Wang, J. M. Wang, and Y. C. Zhang, Late Cenozoic magnetostratigraphy (11-0 Ma) of the Dongshanding and Wangjiashan sections in the Longzhong Basin, western China, Geologie en Mijnbouw, 76, 121-134, $1997 \mathrm{~b}$.

Lowrie, W., and D. V. Kent, Geomagnetic polarity timescale and reversal frequency regimes, this volume, pp. 117-129.

Lowrie, W., and L. Lanci, Magnetostratigraphy of Eocene-Oligocene boundary sections in Italy: No evidence for short subchrons within chrons 12R and 13R, Earth Planet. Sci. Lett., 126, 247-258, 1994.

Lund, S. P., G. Acton, B. Clement, M. Hastedt, M. Okada, T. Williams, and L.S. Party, Geomagnetic field excursions occurred often during the last million years, EOS, Trans. AGU, 178-179, 1998.

Merrill, R. T., M. W. McElhinny, and P. L. McFadden, The Magnetic Field of the Earth: Paleomagnetism, the Core, and the Deep Mantle, 531 pp., Academic Press, San Diego, 1996.
Miller, K. G., M. D. Feigenson, J. D. Wright, and B. M. Clement, Miocene isotope reference section, Deep Sea Drilling Project Site 608: an evaluation of isotope and biostratigraphic resolution, Paleoceanography, 6, 33-52, 1991.

Roberts, A. P., and J. C. Lewin-Harris, Marine magnetic anomalies: evidence that 'tiny wiggles' represent short-period geomagnetic polarity intervals, Earth Planet. Sci. Lett., 183, 375-388, 2000.

Roperch, P., G. Herail, and M. Fornari, Magnetostratigraphy of the Miocene Corque basin, Bolivia: Implications for the geodynamic evolution of the Altiplano during the late Tertiary, J. Geophys. Res., 104, 20,415-20,429, 1999.

Rösler, W., and E. Appel, Fidelity and time resolution of the magnetostratigraphic record in Siwalic sediments: high-resolution study of a complete polarity transition and evidence for cryptochrons in a Miocene fluviatile section, Geophys. J. Int., 135, 861-875, 1998.

Ruddiman, W. F., R. B. Kidd, E. Thomas, and e. al, Site 608, in: Init. Rep. DSDP, edited by W. F. Ruddiman, R. B. Kidd, and E. Thomas, pp. 149-246, U.S. Government Printing Office, Washington, D.C., 1987.

Schneider, D. A., Paleomagnetism of some Leg 138 sediments: Detailing Miocene magnetostratigraphy, Proc. ODP Sci. Res., 138, 59-72, 1995.

Schneider, D. A., J. Backman, W. P. Chaisson, and I. Raffi, Miocene calibration for calcareous nannofossils from low-latitude Ocean Drilling Program sites and the Jamaican conundrum, GSA Bull., 109, 1073-1079, 1997.

Singer, B. S., K. A. Hoffman, A. Chauvin, R. S. Coe, and M. S. Pringle, Dating transitionally magnetized lavas of the late Matuyama Chron: Toward a new ${ }^{40} \mathrm{Ar} /{ }^{39} \mathrm{Ar}$ timescale of reversals and events, J. Geophys. Res., 104, 679-693, 1999.

Tauxe, L., and P. Hartl, 11 million years of Oligocene geomagnetic field behaviour, Geophys. J. Int., 128, 217-229, 1997.

Tauxe, L., and N. D. Opdyke, A time framework based on magnetostratigraphy for the Siwalik sediments of the Khaur Area, Northern Pakistan, Paleogeogr., Paleoclimatol. Paleoecol., 37, 43-61, 1982.

Van Vugt, N., J. Steenbrink, C. G. Langereis, F. J. Hilgen, and J. E. Meulenkamp, Sedimentary cycles in the early Pliocene lacustrine sediments of Ptolemais (NW Greece) correlated to insolation and to the marine Rossello section (S. Italy), Earth Planet. Sci. Lett., 164, 535-551, 1998.

Weeks, R. J., A. P. Roberts, K. L. Verosub, M. Okada, and G. J. Dubuisson, Magnetostratigraphy of upper Cenozoic sediments from leg 145, North Pacific Ocean,, Proc. ODP Sci. Res., 145, 491-521, 1995.

D. V. Kent, Department of Geological Sciences, Rutgers University, Piscataway, New Jersey 08854, and Lamont Doherty Geological Observatory, Palisades, New York 10964. (dvk@1deo. columbia.edu)

W. Krijgsman, Paleomagnetic laboratory "Fort Hoofddijk", Utrecht University, Budapestlaan 17, 3584 CD Utrecht, Netherlands. (krijgsma@geo.uu.nl) 